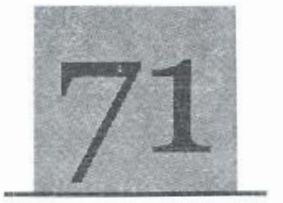

\title{
Climate change: Mitigation and adaptation strategies in fisheries and aquaculture in Nigeria
}

\author{
Magawata, I. / Ipinjolu, J. K.
}

\begin{abstract}
This paper examined possible mitigation and adaptation measures in small-scale fisheries, aquaculture and the fishing communities in Nigeria to cope with the impact of climate change. It is recognized that mitigation measures in fisheries are limited but must consider possibie options on the inputs, equipment and methods employed in fishing and fish processing activities. Several opportunities for adaptation options in the country's artisanal fisheries and aquaculture, and by the fishing communities, to reduce their vulnerability to climate change impacts, and protect the livelihoods and food security have been identified. The areas of research on climate change to enhance knowledge un ine socioeconomic, biologicul und ecological impacts, and to guide decision on mitigation and aduplation measures, in fisheries and aquacuiture and the fishing communities, are also outlined. Proper integration of fisheries and aquaculture into the national policy on climate change and the political will for implementation are key to effective climate change mitigation and adaptation to ensure sustainabie fisheries, and to protect the livelihoods and food security in the couniry.
\end{abstract}

\section{Introduction}

T

The phenomenon of climate change is, perhaps, one of the most current challenges facing man in various socioeconomic endeavours, and it is anticipated that this will continue to be so in decades ahcad. The issues to the shift in the global weather pattern with respect to understanding the causes, impact, mitigation and adaptive stratcgies have assumed socio-cultural, economic, political, biological and technological dimensions. The United Nations Framework Convention on Climate Change (1994) defines climate change as a change of climate which is attributed, directly or indirectly, to human activities that alter the composition of the global atmosphere and which are in addition to natural climate variability observed over comparable time periods.

There are considerable litcratures on the main causes of climate change, and the impacts on environmental resources and inhabitants in many regions of the world. Among the several reports relevant to fisheries and aquaculture include those of the IPCC (2007), FAO (2008), World Fish Centre (2009), Medugu (2009), Halls (2009) and Williams and Rota (2013). The World Fish Centre (2009) reportcd that the productivity, distribution and seasonality of fisheries, and the quality and availability of the habitats that supports them, are sensitive to climate change effects, and that the many fishery-dependent communities and aquaculture operations are in regions highly exposed wo climate change. Therefore, the major challenge is coping with changes in fisheries systcm brought about by climale change.

lisheries is a food production system that is composed of habitat or water body, the fish population and the users who are mainly the fishermen. These sub-systems are intricately related, and the impact of climate change on any one of them will directly or indirectly impact negatively or positively on the others, and on the generality of the communities that depend on them. With focus on the characteristies of the Nigeria fisherics industry, this paper examined possible mitigation and adaptation strategies to combat the impact of climate change on fisheries and aquaculture with focus on Nigeria.

\section{Mitigation measures}

A policy bricf paper by several organizations (2013) identitied three specific adaptation and mitigation measures specifically required for fisheries and aquaculture sector. These are the ability of the measures to improve the management of fisheries and aquaculture and the integrity of aquatic ecosystems, response to the threats and opportunities to food and livelihoods security and help the sector to reduce greenhouse. However, while much opportunities are available for adaptation strategies in fisher- 
ies and aquaculture, the mitigation measures seems to be limited and their effectiveness in combating climate change are still subject to thorough scientific investigations.

Halls (2009) noted that in a small-scale unmechanized fisheries, such as the inland or freshwater and coastal artisanal fisheries in Nigeria, the scope for climate change mitigation through reduction in $\mathrm{CO} 2$ emissions or reversing the global warming trend is very limited. The mitigation strategies often suggested that fisheries include promoting the use of fuelefficient fishing vessels and methods, removing such disincentives to energy efficiency as fuel subsidies, and reducing overcapacity in global fishing fleets, as there are too many boats burning too much fuel to chase too few fish (Oyebanjo, 2010).

Conserving fuel wood during fish smoking through efficient use of small quantity of wood to smoke large quantity of fish according to IPCC (2007) could help a great deal in the mitigation of climate change. The same author explained that another strategy is the use of gas smoking kilns or solar powered dryers. These methods have very negligible emission to the atmosphere and hence less damaging to the environment.

\section{Adaptation strategies}

Several adaptation measures to the impacts of climate change on fisheries and aquaculture and the fishing communities that depend on the resources for livelihoods have been suggested (WorldFish, 2007; Halls, 2009; Williams and Rota, 2013; Wikipedia, 2013). Adoption of coping strategies to the impacts of climate change is a must for artisanal fisheries system and the rural fishing communities who contributes very little to global warming but inevitably suffer more for the negatives effects. However, the appropriateness and effectiveness of these measures would depend on the characteristics and vulnerability of the fisheries and the fishing communities.

The following sections outlined some possible adaption options in artisanal fisheries and aquaculture in Nigeria

a. The country's capture fisheries which have suffered depletion through stress factors such as overfishing and pollution, and now being compounded by changes in climate, should be on continuous well planned restocking programme to reduce their vulnerability.

b. Protecting the resilience of the freshwater and coastal waters, by avoiding habitat destruction and pollution that could fiurther aggravate stress on the systems.

c. De-silting of the natural water hodies, (rivers, lakes, crecks and rescrvoirs) to prevent drying-up which has already manifested in zones across the country.

d. Control of fishing effort and limiting the quantity of fish caught to reduce overfishing as ways of protecting the water bodies and the resourec poor fishermen.

c. Integration of fishing or aquaculure with agriculture to diversify the economy and empower the communities to secure their means of livelihoods.

f. Training opportunitics and financial assistance to reduce vulnerability of the fishing communities to the impacts of climate change.

g. Development, adaptation and adoption of appropriate fish post-harvest teclinology to reduce huge loss incurred in the rural fishing communities and make-up for reduced fish production arising from the impact of climate change.

b. Plan of action, through the National Emergency Management Agency, to protect fishing communities from immediate impact of climate change such as floods, displacement and disease outhreak.

i. Expansion of aquaculture to increase and stabilize fish food supplies and employment to protect livelihoods of communitics, and to augment wild stocks.

j. Lxpansion of fish farming in the expanded flooded plains of rivers, reservoirs and fadama areas

k. More attention to mariculure in view of the anticipated impacts of elimate change on freshwater aquaculture.

1. Promolion of fish culture in cages and irrigation canals of the reservoirs to enhance livelihoods of the communities

m. Integration of fish culture with crops and/or poultry to ensure efficient utilization of environmental resources, production inputs and infrastructure to enhance livelihoods and food security

n. Promote the culture of planktophagous and herbivorous fishes that feed at the lower level of fond chain and others such as seaweed and shellfish which, according to FAO (2009), could help to sequester carbon.

o. Improvement of the microclimatic conditions of fish farms, natural waters and the larger environment through planting of shrubs and vegetables around pond areas, orchards/scmi-deep rooting trees around natural water bodies and massive afforestation programme.

p. Support innovation by research on management systems and aquatic ecosystems.

q. Political will to implement adaptation strategies.

r. Integration of fisheries and aquaculture into Nigeria's policy on climate change.

\section{Research Needs}

There should be reliable and current seientific information to enhance knowledge on the dynamics of climate change; the impacts on capture fisheries, fishing communitics and aquaculture; as well as on the mitigation and adaptation strategies. Therefore, some issues that could be subject for immediate, medium and long term research activities of scientists and other stakcholders in fisheries and aquaculture in Nigeria are itemized in the following sections.

a. Indices, trends and dynamics of climate change in the country and the neighbour regions

b. Quantitative information on the biological and ecological indices and effects of climate change

c. Surces and contributions of fisheries and aquaculture to climate change at the local and regional level 
d. Impacts of climate change on individual fish species, fish population, other aquatic resources, fish ponds and other fish culture systems in the country's inland and coastal water bodies

c. Vulnerability and response of artisanal and industrial fisheries, as well as aquaculture, to changing weather pattern

f. Evaluation of the effectiveness of fcasible mitigation measures in fisheries and aquaculture.

g. Innovations on adaptive options in fisheries and aquaculture, and the fishing communities

h. Effect of adaptation measures by other sectors on fisheries and aquaculure

i. Forecasting and early warning mechanisms on the immediate impacts of clinate change

j. Scientific framework for incorporation of fisherics and aquaculture in a national policy on climate change

\section{Conclusion}

Climate change is inevitably a challenge for fisheries and aquaculture management/production. Rigorous research on impacts. mitigation and adaptation combined with practical actions, locally, nationally, regionally and globally will provide knowledge to the solution of the problem. Empirical evidences on the effectiveness of mitigation and adaptation measures should be put in place to ensure scientific approach to the problem at hand. To this end, measures of weather monitoring and forccasting need to be intensified. High-quality research that involves resource users, build strong partnerships and harness political will for implementation of the adaptation and the mitigation measures is crucial for making fisheries and aquaculture systems more resilient to the challenge of global climate change and securing a bright future for the people that depend upon them.

\section{REFERENCES}

FAO (2009). Yearbook of fisheries statistics-fishery commodilies. FAO Series No, 65, Rome, Italy, 187.

Halis, A.S. (2009). Addressing fisheries in the climate change and adaptation initiative: Fisheries Research and Development in the

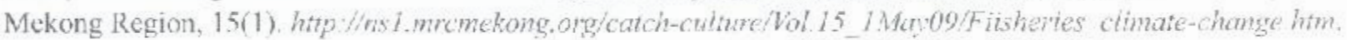

IPCC (2007). Summary for pulicymakcrs. In Parry, M. L. Canziari, O. F., Palutikof, J. P., Vander-Linden, P. J. and Hanson, C. E. (eds.). Climate Change 2007. Inpasts, Adaptation and Vuthrubility. Contribuion of working Group II to the Fourth Assessment Report of the Intergovernmental Panel on Climate Change. Cambridge University Press.

Medugu, N. I. (2009). Nigeria: Climate change: A threat to the country's developmont, Daily: Trust. July 14,2009

Oyebanjo, I. (2010). Climate change: What Vigeria must do. NBF News. Free Home 7/3/2010.

Reed, W. Burchard, J., Hopson, A. J., jennes, J., Yaro. I. (1967), Fish and Fisheries of Northern Nigeria. Ministry of Agriculture, Northern Nigeria. Zaria: Gaskiya Prcss. 226pp.

UNEP (2013). Fisheries and aquaculture in a changing climatc. HAO, WorldFish, ICES, NACEE, ete, http: $/$ www.unep.org/ ecosystemmanagement/Portals/7/Documents/policy_brief_EM-MCE-ca.Pisheries.pdf.

UNFCC, (1994). United Nations Framework Cunvention on Climate Change: Text, UNEP/WMO, Geneva.

Wikipedia, Climate Change! It's impact on the environment. htip:/wwwspringerlink.com/content/17m32u6757011331.

Williams, L. and A. Rota (2013). Impact of climate change on fisheries and aquateulture in the developing world and opportunities for adaptation. Fisheries thematic paper: tool for project design. www.itadiorg/rkm/pub/fisheries.pdf.

Worldfish (enter (2007). Fisheries and aquaculture can provide solutions to cope with climate change. www.worldfishecnter.org. resource centre/CC. Threat to Fishorics 1701 -pdf.

(2010). Climate Change Challenges Facing Fisheries and Aquacuiture. Penang, Malaysia. 12p 